\title{
PENDIDIKAN AKHLAQ PENDAKWAH DALAM SURAT MARYAM AYAT 41-50 MENURUT TAFSIR FATHUL QODIR
}

\author{
Muhammad Utama al-Faruqi \\ Magister Ilmu Agama Islam Universitas Islam Indonesia, Yogyakarta, \\ Indonesia \\ bung.faruqi@gmail.com \\ DOI: 10.20885/tarbawi.vol13.iss2.art3
}

\begin{abstract}
$D a^{\prime}$ wah is one of the pillars of upholding the noble religion of Islam. As a form of worship for the perpetrators, and a way of calling out the truth to people outside of Islam, or who are in Islam. So, it is very necessary to have serious attention in instilling the characteristics of the da'wah implementers, or the preachers. Especially in their morality, as one of the most important assets in the success of the da'wah. Given that in the present era, there are so many people who dedicate themselves to da'wah, but in reality, they are the ones who destroy the image of Islam and the preaching itself with their bad behavior and morals. In the Al Quran, in Surah Maryam verses 41 to 50, the dialogue of the Prophet Abraham - 'alayhis salam - is narrated as one of the most important role models for preachers across generations. The preacher must have intellectual and emotional intelligence, must be patient and elegant. Without criticizing and making people run away from the religion. In fact, the characteristics of Muslims in Indonesia are the characteristics of being gentle, friendly, and cooperative. These findings contribute to the preachers so that what they preach brings many benefits, not harm.
\end{abstract}

Keywords: Education; Morality; Preacher; Maryam; Interpretation 


\title{
el-Tarbawj Muhammad Utama al-Faruqi
}

\begin{abstract}
Abstrak
Dakwah merupakan salah satu pilar tegaknya agama Islam yang mulia. Sebagai salah satu bentuk ibadah bagi para pelakunya, dan menjadi salah satu cara menyerukan kebenaran baik pada orang-orang di luar agama Islam, atau yang berada dalam agama Islam. Maka, sangat diperlukan sekali adanya perhatian serius dalam menanamkan karakteristik pelaksana dakwah, atau para pendakwah. Terlebih dalam akhlaq mereka, sebagai salah satu modal terpenting dalam kesuksesan dakwah tersebut. Mengingat pada era sekarang banyak sekali orang yang menisbatkan diri pada dakwah, akan tetapi pada realitanya, mereka justru yang merusak citra Islam dan dakwah itu sendiri dengan perilaku dan akhlaq mereka yang kurang baik. Dalam Al Quran, pada surat Maryam ayat 41 hingga 50 dikisahkan dialog Nabi Ibrahim -'alayhis salam- sebagai salah satu teladan terpenting bagi para pendakwah lintas generasi. Pendakwah harus memiliki kecerdasan intelektual dan emosional. Harus sabar dan elegan. Tanpa mencela dan membuat mereka lari dari agama yang notabene karakteristik umat Islam di Indonesia adalah karakteristik yang lembut, ramah, dan gotong royong. Penemuan ini memberikan kontribusi kepada para pendakwah agar apa yang mereka sampaikan membawa banyak manfaat bukan mendatangkan mudharat.
\end{abstract}

Kata Kunci: Pendidikan; Akhlaq; Pendakwah; Maryam; Tafsir

\section{Pendahuluan}

Dakwah merupakan salah satu kegiatan terpenting dalam penyebaran ajaran Islam, selain pengajaran atau pendidikan. Maka, jika dilihat dari aspek sejarah, agama Islam mulai dikenal dan kemudian diakui dengan dakwah, dan dengan hal-hal yang berkaitan dengan dakwah tersebut, seperti syarat-syarat pendakwah, etika, dan tata cara yang diajarkan dalam agama Islam. Dakwah juga berfungsi sebagai penguat keislaman dan keimanan internal kaum Muslimin sendiri, karena sewajarnya secara fitrah setiap manusia memiliki 
kebutuhan rohani. Yang dimana kebutuhan rohani ini berkaitan erat dengan kondisi psikologi dan fisik seseorang. Setelah memperhatikan betapa pentingnya dakwah, maka sepertinya hal-hal terkait dengan dakwah ini harus diperhatikan dengan baik, agar terlaksana dengan baik pula dengan kontinyu. Terlebih pada pendidikan para pendakwah, para pelaksana praktek ini harus diberikan bekal yang cukup dengan pengarahan yang jelas, karena mereka juga membawa citra agama Islam dihadapan publik, terlebih khusus masyarakat Islam. Jika tidak diperhatikan, maka bisa saja para pendakwah tidak mempraktikkan tata cara dan etika dakwah dalam kegiatan mereka, kemudian membuat citra dakwah Islam mulai dicitrakan negatif secara perlahan di hadapan publik, dan bahkan di hadapan umat Islam sendiri, yang kemudian berujung pada kaderisasi pendakwah dan pendidikan pendakwah yang bisa terancam terhenti sebagai kemungkinan buruk terbesar yang diawali oleh hal-hal kecil tersebut.

Hal seperti ini sudah terjadi beberapa tahun terakhir, semenjak media sosial sudah menjadi kebutuhan pokok dan hampir semua orang memilikinya, seolah setiap orang mampu menjadi pendakwah yang baik, berilmu tinggi, dan merasa lebih hebat daripada para konsumen kontennya atau produsen konten yang lain. Suatu hal yang menyebabkan para masyarakat kesulitan dalam menentukan konsumsi mereka di media sosial. Sebagian dari para pendakwah ini bisa saja dikatakan bahwa mereka mampu menyajikan wawasan ilmu agama mereka yang luas, sementara sebagian mereka yang lain dikenal masyarakat luas karena fenomenal. Akan tetapi, dalam konten mereka, mereka seolah melupakan salah satu hal yang penting, yaitu akhlaq. Yang dimana pada saat awal masa kenabian, akhlaq merupakan salah satu, bahkan satu-satunya modal pokok Nabi Muhammad -shallallahu 'alayhi wa sallam- dalam mengenalkan ajaran Islam pada kaumnya, begitu juga para nabi dan rasul terdahulu. Sebagaimana firman Allah : 


\section{el-Tarbawj Muhammad Utama al-Faruqi}

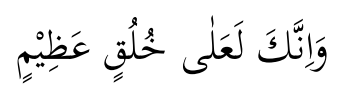

Dan sesungguhnya engkau benar-benar berbudi pekerti yang luhur.(Tim Kemenag RI, 2006)

Jika ayat di atas direnungi, maka bisa disimpulkan bahwa Allah tidak memuji utusan-Nya dengan kekayaan, popularitas dan lain-lain. Akan tetapi pada akhlaqnya, maka kemuliaan akhlaq ini pula yang membuat dakwah pada masa itu diterima, walaupun banyak halangan yang ada. Karena keluhuran akhlaq ini pula, masyarakat Makkah saat itu mempercayai Nabi Muhammad -shallallahu 'alayhi wa sallam-di periode awal dakwah jahriyah (terang-terangan). Karena akhlaq para pendakwah inilah yang menjadi representasi dari dakwah yang dibawanya. Hal ini tampak sangat jelas dalam sebuah hadits yang diriwayatkan oleh Imam Bukhari dalam Bab Tafsir dengan nomor hadits 4770, mengenai tafsir dari firman Allah dalam surat Asy Syu'ara ayat 214, "dan berilah peringatan pada kerabat dekatmu". Diriwayatkan dari Ibnu Abbas - radhiyallahu 'anhuma-, bahwa setelah ayat tersebut turun, Nabi Muhammad -shallallahu 'alayhi wa sallamkemudian mendaki ke atas bukit Shofa, dan kemudian memanggil segenap kaum Quraisy untuk berkumpul di bawah bukit Shofa tersebut, lalu para kaum Quraisy berkumpul, bahkan jika ada diantara mereka tidak mampu untuk keluar dari rumahnya, mereka mengutus seseorang untuk mendengarkan apa yang akan disampaikan oleh Nabi Muhammad -shallallahu 'alayhi wa sallam-. Bahkan hadir pula diantara mereka Abu Lahab dan para pembesar kaum Quraisyi, lalu Beliau berkata "bagaimana menurut kalian, jika aku mengabarkan pada kalian bahwa di lembah sana, akan ada sekelompok penunggang kuda yang ingin berbuat sesuatu atas kalian, apakah kalian akan mempercayaiku ?". Lalu mereka menjawab, "ya, tentu saja. Kami tidak pernah mendengarkan sesuatu darimu kecuali kejujuran". Lalu Beliau berkata, "Sesungguhnya aku adalah pemberi peringatan bagi kalian semua, tentang siksaan yang keras". Lalu Abu Lahab berkata, 
"celakalah dirimu ! apakah hanya karena ini engkau mengumpulkan Kami ?" lalu turunlah ayat "celakalah kedua tangan Abu Lahab, dan sungguh celakalah ia, tiada berguna harta bendanya dan apa yang dia usahakan".(al-Bukhari, 2011, p. 788)

Dari peristiwa di atas, bisa dilihat bagaimana pengaruh karakter seorang yang dikenal oleh masyarakatnya, ketika akan menyampaikan sesuatu, terlebih seorang pendakwah yang menyampaikan nasehat kebaikan dan kebenaran, selayaknya menghiasi diri dengan akhlak atau kepribadian yang baik. Maka pendidikan para pendakwah, sebenarnya telah ditentukan secara jelas dalam Al Quran dan Al Hadits sebagai pokok yang paling mendasar dalam ajaran Islam. Maka, akan nampak dalam kedua dasar agama Islam tersebut bahwa yang menjadi prioritas dalam dakwah bukanlah penampilan dan aksesoris (kholqiyah), akan tetapi karakter mulia (khuluqiyah). Kemuliaan akhlaq masyarakat umum adalah tujuan dari dakwah, sedangkan kemuliaan akhlaq dai merupakan alat perantara untuk mencapai hal itu. Di dalam ajaran Islam, ajaran untuk mengimani dan mempercayai dengan sepenuh hati bahwa Allah subhanahu wa ta'ala- telah mengutus nabi dan rasul untuk memperingatkan umat manusia adalah ajaran yang paling mendasar dan juga penting. Jumlah para nabi dan rasul inipun sebenarnya amat sangat banyak, akan tetapi yang disebutkan dalam Al Quran hanyalah 25 nabi dan rasul. Seolah menjadi isyarat bahwa seorang pendakwah tidak boleh berambisi untuk terkenal, karena selain 25 nabi dan rasul ini, ada ratusan bahkan ribuan nabi dan rasul lain yang tidak disebutkan dalam Al Quran, akan tetapi keberadaan mereka disebutkan oleh Nabi Muhammad -shallallahu 'alayhi wa sallamwalaupun tidak rinci. Salah satu hikmah dari disebutkannya kisah 25 nabi dan rasul dalam Al Quran ini, adalah agar para pendakwah dari kalangan umat Islam lintas masa dan generasi mampu menjadikan para nabi dan rasul sebagai teladan dalam menjalani kehidupan pada 


\section{el-Tarbawj Muhammad Utama al-Faruqi}

umumnya, dan menjadikan mereka sebagai teladan yang baik dalam berdakwah, pada khususnya.

Salah satu diantara 25 nabi dan rasul itu adalah Nabi Ibrahim 'alayhis salam- yang memiliki nama julukan "Khalilurrahman" atau kekasih Allah, dan juga "Abul Anbiya"' atau bapak para nabi, mengingat dari keturunan Nabi Ibrahim ini muncul para nabi setelahnya, yaitu Nabi Ishaq yang diutus untuk Bani Israil beserta para keturunannya, dan Nabi Isma'il yang menjadi bapak bangsa Arab, yang kemudian dari keturunan Nabi Isma'il ini, lahirlah Nabi Muhammad -shallallahu 'alayhi wa sallam-. Akan tetapi, tentu saja pembahasan khusus mengenai Nabi Ibrahim ini tidak kemudian menafikan kemuliaan Nabi Muhammad -shallallahu 'alayhi wa sallam-. Akan tetapi dalam kisah Nabi Ibrahim disini terdapat banyak hikmah dan pelajaran yang tidak ditemukan dalam sirah Nabi Muhammad shallallahu 'alayhi wa sallam-, yaitu mengenai kisah dialog Nabi Ibrahim dengan ayahnya yang menjadi seorang penyembah berhala, bahkan diriwayatkan bahwa ayahnya adalah seorang pembuat patung berhala. Dalam pembahasan ini, kitab tafsir Fathul Qadir karya Al Imam Asy Syaukani menjadi pilihan referensi utama yang didukung dengan beberapa kitab tafsir ulama lain seperti Fakhruddin Ar Razi, Al Alusi, Abu Hayyan Al Andalusi, dan lain sebagainya. Mengingat bahwa kitab tafsir Fathul Qadir ini selain memiliki kandungan tafsir yang berdasarkan dirayah (pengetahuan dan pemahaman) dan riwayah (riwayat terdahulu), juga memiliki tingkat kesulitan terlebih dalam segi bahasa. Maka, dengan adanya beberapa kitab tafsir lain tersebut dengan tujuan mampu memberikan pemahaman yang lebih jelas, lebih mudah dan memberi wawasan pengetahuan yang lebih banyak dan mendalam.

Tentu dalam ilmu tafsir akan ditemukan banyak hal yang menarik untuk terus dibahas. Seperti perbedaan pendapat diantara ulama, walaupun perbedaan ulama dalam tafsir lebih cenderung 
perbedaan yang bersifat tanawwu' atau dari segi jenis dan makna, tanpa bertentangan satu sama lain. Berbeda dengan perbedaan ulama dalam ilmu fiqih, seringkali perbedaan pendapat yang bersifat tadhod atau berlawanan. Sehingga dalam satu permasalahan fiqih, bisa ditemukan hingga lebih dari empat pendapat yang berbeda-beda dalam segi hukum. Akan tetapi kedua jenis perbedaan ini akan dipilih satu pendapat yang dianggap terbaik, yang pemilihan pendapat ini biasa disebut sebagai tarjih.

\section{Metode Penelitian}

Metode penelitian yang digunakan sebagai pisau analisis dalam penelitian ini adalah berjenis library research, karena semua data yang digali peneliti disini adalah bersumber dari Pustaka. Penelitian ini lebih memfokuskan pada pencarian naskah dan pendapat ahli tafsir dalam kitab/tafsir Fathul Qodir tentang pendidikan akhlaq. Adapun sumber data primer yang digunakan peneliti disini adalah tafsir Fathul Qodir tentang pendidikan akhlaq pada surat Maryam ayat 41-50, sedangkan sumber sekundernya adalah buku-buku yang membahas pokok permasalahan secara tidak langsung, Adapun data sekunder dalam penelitian yakni buku-buku karangan ilmiah, majalah, artikel yang berhubungan dengan pendidikan akhlaq.

Peneliti menggunakan metode analisis data sebagai pisau analisis dalam penelitian ini dengan Pertama, metode Deskripsi yakni dengan mendeskripsikan realita-realita, fenomena sebagaimana adanya yang peneliti pilih dari perspektif subjektif yakni pemikiran alQur'an surat Maryam ayat 41-50 dengan menggunakan tafsir Fathul Qodir. Kedua, metode analisis yani peneliti menganalisis bab perbab dari tafsir Fathul Qodir untuk mencari pendidikan akhlaq yang terkandung dalam surat Maryam 41-50 kemudian menganalogikan dengan akhlaq pendakwah yang ada khususnya di Indonesia. 


\section{el-Tarbawj Muhammad Utama al-Faruqi}

\section{Hasil dan Pembahasan}

\section{Dakwah dan Hukum Berdakwah}

Dakwah atau da'wah secara etimologis dalam bahasa Arab memiliki banyak definisi. Antara lain, thalab (permintaan), su'al (pertanyaan), nida' (panggilan), tajammu' (perkumpulan), du'a (doa), dan istimalah (permintaan untuk condong pada sesuatu).Maka, $d a^{\prime} w a h$

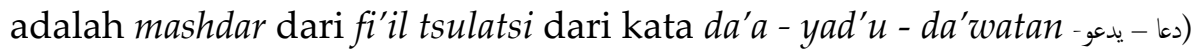
(دعوة. Sebagian bangsa Arab mengganti ta' marbutah (:) di akhir kata $d a^{\prime} w a h$ dengan alif, maka menjadi da'wa yang bermakna do'a.(al'Ammar, 2018, p. 17) Sedangkan secara terminologis, dakwah merupakan sebuah lafadz yang sudah terikat dengan Islam dan risalah dan pada tatacara penyebarannya, penyampaiannya hingga penjelasannya pada semua orang. Maka, dakwah bisa diartikan sebagai upaya penyebaran dan penyampaian, dan menjadi sebuah ilmu tersendiri yang memiliki pembahasan tersendiri, keistimewaan, tujuan-tujuan, metode-metode dan perantara-perantaranya.(al'Ammar, 2018, p. 21)

Maka, $d a^{\prime} i$ adalah $f a^{\prime} i l$ (pelaku) dari $d a^{\prime} w a h$, yang terkadang selain disebut sebagai $d a^{\prime} i$, mereka juga biasa disebut sebagai muballigh, murabbi dan pendakwah. Adapun berdasarkan kultur dakwah Islam di Indonesia, mereka lebih biasa disebut ustadz atau ustadzah. Walaupun penyebutan ustadz atau ustadzah ini pada awal mulanya hanya terbatas pada para pengajar yang membantu kyai di pondok pesantren. Para ulama bersepakat bahwa hukum melakukan dakwah adalah fardhu (wajib), akan tetapi para ulama berbeda pendapat mengenai jenis kewajiban tersebut, antara fardhu 'ain (wajib untuk semua orang) atau fardhu kifayah (wajib untuk sekelompok orang saja). Ada juga yang berpendapat dengan menyatukan kedua perbedaan diatas bahwa hukum berdakwah adalah fardhu kifayah 
berdasarkan tempat atau negara yang ditempati para pendakwah, karena setiap negara, setiap tempat membutuhkan seorang atau sekelompok pendakwah beserta kegiatan dakwahnya. Maka, jika hal ini sudah dilakukan oleh sekelompok orang yang berdakwah, maka kewajiban bagi sebagian muslim yang lain telah gugur. Akan tetapi, gugurnya kewajiban sekelompok orang yang tidak berdakwah itu tidak kemudian menghalangi mereka untuk berdakwah, hukum dakwahnya mereka menjadi sunnah muakkadah (sunnah yang dianjurkan), karena jika tidak ada satupun orang Islam yang berdakwah di satu negara atau satu tempat, maka seluruh penduduk negara tersebut akan mendapatkan dosa.(Ali, 2004, p. 8)

\section{Tafsir Surat Maryam Ayat 41-50 (dalam TafsirFathul Qodir)}

Surat Maryam tergolong surat Makiyyah dan terdiri dari 92 ayat. Surat makiyah adalah surat yang diturunkan sebelum hijrahnya kaum Muslimin ke kota Yatsrib (Madinah).(al-Utsaimin, 2013, p. 20). Berdasarkan riwayat dari An Nuhhas dan Ibnu Marduweyh dari Ibnu Abbas berkata, bahwa surat (Sone) atau surat Maryam diturunkan di Makkah.(al-Syaukani, 2014a, p. 442)

Hal-hal yang menjadikan surat ini termasuk sebagai surat Makkiyah ditinjau selain dari riwayat tersebut adalah karena surat ini dari segi tema, surat ini dibuka dengan huruf hijaiy kalimat yang terdiri dari huruf-huruf hijaiyyah yaitu (كهـــ , lalu di dalamnya memuat kisah-kisah para Nabi dan umat-umat terdahulu, dan

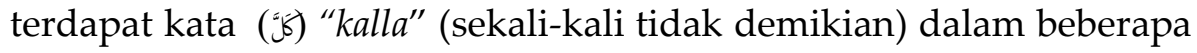
ayat-ayatnya. Sedangkan dari segi tata bahasa dan materi yang terkandung, di dalam surat ini terdapat materi tentang seruan untuk mengesakan Allah, dan juga pengukuhan kerasulan Nabi Muhammad -shallallahu 'alayhi wa sallam-, dan juga balasan serta adzab atau siksaan, kemudian penggunaan pilihan kata yang pendek, akan tetapi 


\section{el-Tarbawj Muhammad Utama al-Faruqi}

memiliki makna yang sangat mendalam. Sedangkan surat Maryam ayat 41-50 beserta terjemahnya adalah sebagai berikut :

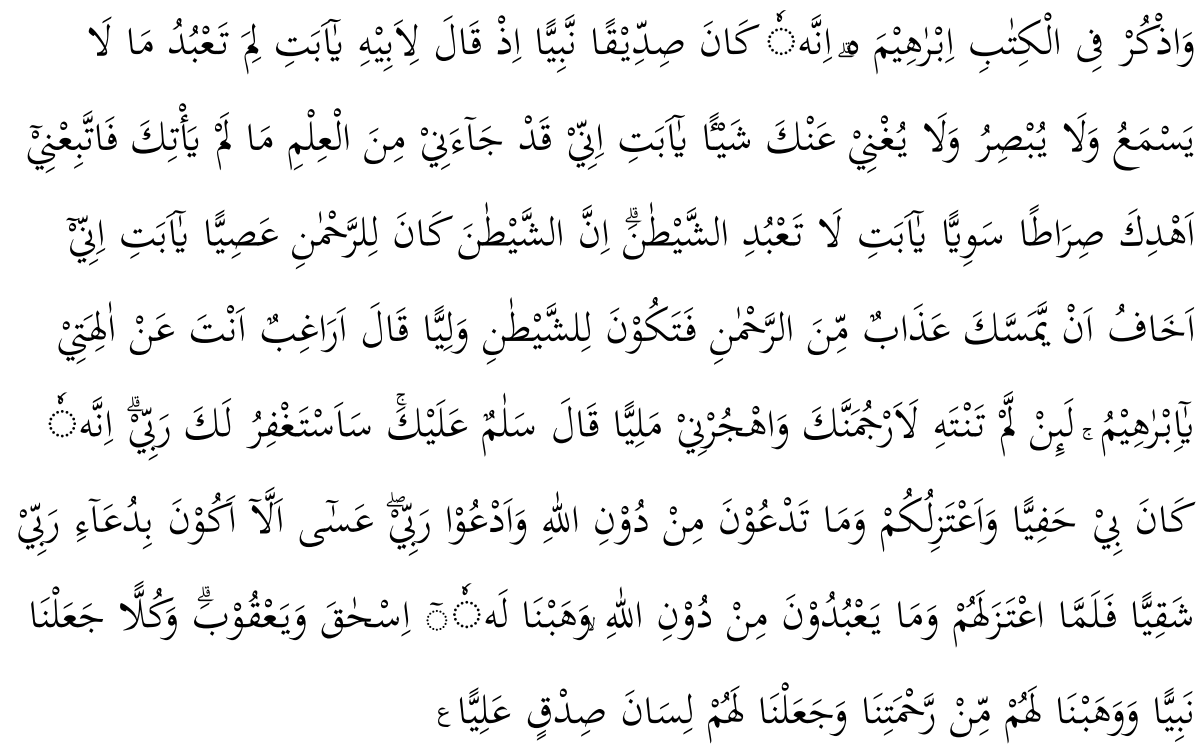

41. Dan ceritakanlah (Muhammad) kisah Ibrahim di dalam Kitab (AlQur'an), sesungguhnya dia adalah seorang yang sangat membenarkan, seorang Nabi. 42. (Ingatlah) ketika dia (Ibrahim) berkata kepada ayahnya, "Wahai ayahku! Mengapa engkau menyembah sesuatu yang tidak mendengar, tidak melihat, dan tidak dapat menolongmu sedikit pun? 43. Wahai ayahku! Sungguh, telah sampai kepadaku sebagian ilmu yang tidak diberikan kepadamu, maka ikutilah aku, niscaya aku akan menunjukkan kepadamu jalan yang lurus. 44. Wahai ayahku! Janganlah engkau menyembah setan. Sungguh, setan itu durhaka kepada Tuhan Yang Maha Pengasih. 45. Wahai ayahku! Aku sungguh khawatir engkau akan ditimpa azab dari Tuhan Yang Maha Pengasih, sehingga engkau menjadi teman bagi setan." 46. Dia (ayahnya) berkata, "Bencikah engkau kepada tuhan-tuhanku, wahai Ibrahim? Jika engkau tidak berhenti, pasti engkau akan kurajam, maka tinggalkanlah aku untuk waktu yang lama." 47. Dia (Ibrahim) berkata, "Semoga keselamatan dilimpahkan kepadamu, aku akan memohonkan ampunan bagimu kepada Tuhanku. Sesungguhnya Dia sangat baik kepadaku. 48. Dan aku akan menjauhkan diri darimu dan dari apa yang engkau sembah selain Allah, dan aku akan berdoa kepada Tuhanku, mudah-mudahan aku 
tidak akan kecewa dengan berdoa kepada Tuhanku." 49. Maka ketika dia (Ibrahim) sudah menjauhkan diri dari mereka dan dari apa yang mereka sembah selain Allah, Kami anugerahkan kepadanya Ishak dan Yakub. Dan masing-masing Kami angkat menjadi nabi. 50. Dan Kami anugerahkan kepada mereka sebagian dari rahmat Kami dan Kami jadikan mereka buah tutur yang baik dan mulia. (Tim Kemenag RI, 2006)

Rangkaian ayat diatas merupakan dialog antara Nabi Ibrahim dengan ayahnya yang bernama Azar, yang merupakan bentuk dialog secara lebih detail dari Surat Al An'am ayat 74 :

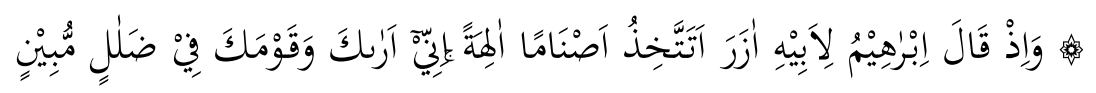

74. Dan (ingatlah) ketika Ibrahim berkata kepada ayahnya Azar, "Pantaskah engkau menjadikan berhala-berhala itu sebagai tuhan? Sesungguhnya aku melihat engkau dan kaummu dalam kesesatan yang nyata." (Tim Kemenag $R I, 2006)$

Pada ayat ini para ulama berbeda pendapat mengenai nama Nabi Ibrahim yang sebenarnya. Akan tetapi, mayoritas ulama telah bersepakat bahwa nama ayah Nabi Ibrahim yang tepat adalah Azar, dengan berdasar riwayat paling kuat dari pendapat Adh Dhahhak, dengan riwayat dari Ibnu Abbas.(Syakir, 2005, p. 789) Imam Asy Syaukani berkata, bahwa firman Allah (واذكر) "wadzkur" yang berarti "ingatlah" merupakan kata yang bertautan dengan kata (أنذر) "andzir" atau "berilah peringatan" yang terdapat pada ayat sebelumnya, yaitu "Dan berilah mereka peringatan (Muhammad) tentang hari penyesalan, (yaitu) ketika segala perkara telah diputus, sedang mereka dalam kelalaian dan mereka tidak beriman. Maksud dari penyebutan Nabi Ibrahim dalam Al Quran, adalah agar dibacakan kisahnya kepada semua orang. Sebagaimana firman Allah, "dan bacakanlah kepada mereka kisah Ibrahim". Lalu, kata (إنّا) "innahu" yang berarti, "sesungguhnya dirinya adalah seorang yang sangat membenarkan (hal-hal yang bersifat ghaib) dan seorang Nabi", merupakan 


\section{el-Tarbawj Muhammad Utama al-Faruqi}

penjelasan perintah sebelumnya kepada Nabi Muhammad-shallallahu 'alayhi wa sallam- untuk menceritakannya pada banyak orang .

Menurut Asy Syaukani kata (صـــن "shiddiq" memiliki makna seorang yang sangat jujur dan kata (نــــ "nabiya” menjadi nashab(fathah) dikarenakan menempati posisi sebagai khabar kedua dari (كان) "kana". Maka dari kata ini, memiliki makna bahwa Nabi Ibrahim memiliki dua sifat mulia yaitu seorang Nabi dan seorang yang sangat jujur.(al-Syaukani, 2014a, p. 462) Menurut Fakhruddin Ar Razi dalam kitab tafsirnya, kata (واذكر) wadzkur" ini bertautan dengan ayat "yang dibacakan (yang disebutkan) ini adalah rahmat dari Rabbmu pada hamba-Nya bernama Zakariya". Fakhruddin Ar Razi lebih jauh mentautkan ayat ini dengan ayat yang berada di awal surat daripada Imam Asy Syaukani sendiri yang mentautkan dengan dua ayat sebelumnya. Sebagaimana Ar Razi menyebutkan bahwa kisah Nabi Ibrahim adalah kisah ketiga dalam surat Maryam setelah kisah Nabi Isa dan kisah Nabi Zakariya. Kemudian, Ar Razi juga menjelaskan hikmah dibalik perintah Allah untuk menyampaikan kisah Nabi Ibrahim kepada kaum Quraisy saat itu.

Yang pertama karena Nabi Ibrahim adalah leluhur bangsa Arab, dan mereka sangat percaya dengan keagungan dan kesucian agama Nabi Ibrahim. Sedangkan mereka mengatakan bahwa mereka menyembah berhala dikarenakan mengikuti jejak para leluhur mereka.Dan Nabi Ibrahim adalah leluhur mereka yang paling mulia dan paling mereka agungkan. Yang kedua, alasan para kaum Quraisy yang masih menyembah berhala saat itu adalah karena mereka menganggap bahwa itulah agama leluhur mereka, jika sebab pertama karena mereka hanya sekedar mengikuti, sedangkan yang kedua mereka menganggap bahwa mereka tahu bahwa beginilah dahulu para leluhur mereka beragama. Sedangkan sebab yang ketiga adalah, karena mereka adalah kaum yang lebih mengutamakan taklid daripada mencari dalil pembenaran. Maka, dengan disebutkan kisah 
Nabi Ibrahim inilah, prinsip taklid mereka akan lemah, karena mereka juga mengenal Nabi Ibrahim sebagai leluhur mereka.

Kemudian Ar Razi juga menafsirkan makna "Shiddiq" dan "Nabiyya". Ar Razi menyebutkan bahwa ada dua pendapat mengenai pemberian sifat kepada Nabi Ibrahim dengan kata "shiddiq" memiliki dua arti, yang pertama adalah menunjukkan pada kejujuran Nabi Ibrahim, seperti yang disebutkan oleh Asy Syaukani, dan yang kedua karena Nabi Ibrahim adalah orang yang sangat mempercayai kebenaran. Dan arti pertama lebih sesuai menurut Ar Razi.(al-Razi, 1981, p. 223) Dari penafsiran ayat ini, bisa diambil sebuah kesimpulan bahwa seorang pendakwah dituntut untuk memiliki sifat jujur. Karena seorang pendakwah muslim yang jujur akan tampak bekas kejujurannya pada wajah dan intonansi suaranya. Karena dahulu Nabi Muhammad -shallallahu 'alayhi wa sallam- pernah berdialog dengan orang-orang yang tidak mengenalnya, dan mereka berkata "demi Allah, dia tidak memiliki wajah seorang pembohong, tidak pula bersuara seperti suaranya seorang pembohong". Dan tentu nampaknya bekas-bekas kejujuran di wajah seorang pendakwah dan pada suaranya memberikan efek kepada lawan bicara dan akan membuatnya menerima apa yang dibawa oleh pendakwah dan bahkan akan menghormatinya. Kecuali jika hatinya telah buta, dan sudah terlanjur parah.(Zaydan, 2005, p. 348)

Kemudian, setelah itu Imam Asy Syaukani menafsirkan ayat setelahnya. (إذ قال لأبيه) “idz qola li abihi” yang bermakna “ketika berkata pada ayahnya", merupakan badal isytimal (badal yang menyeluruh) yang kembali kepada Ibrahim sebagai pelaku pada ayat sebelumnya. Pengaitan peringatan dengan waktu, yang ditujukan untuk memberikan pengingat atas peristiwa-peristiwa yang terjadi saat itu, agar menunjukkan betapa pentingnya peristiwa tersebut. Lalu, huruf “ta'” (تاء) dalam kalimat (يا أبت) “yaa Abati" adalah ganti dari huruf ya' (يـ), maka kedua huruf ini (ta' dan ya') tidak boleh digabungkan, 


\section{$e^{\text {I-Tarbawj Muhammad Utama al-Faruqi }}$}

kemudian dilanjutkan dengan kalimat tanya "mengapa dirimu menyembah..." untuk menyatakan pengingkaran dan sikap kontra " sesuatu yang tidak mampu mendengar" yaitu mendengar apa-apa yang kau katakan, termasuk pujian-pujian kepadanya dan do'a “dan tidak mampu melihat" apapun yang dirimu lakukan.

Termasuk melihat dan mendengar segala sesuatu dalam makna yang lebih umum. "dan tidak mampu memberimu manfaat sedikitpun". Maka berhala-berhala yang disembah Azar itu tidak mampu memberikan keselamatan dan tidak pula menangkal malapetaka. Nabi Ibrahim menyertakan ini sebagai metode dalam memberikan petunjuk dan nasehat. Nabi Ibrahim menyatakan pertanyaan ini dengan panggilan yang baik, yang kemudian dikolaborasikan dengan kelembutan dan kesantunan agar hati ayahnya tertarik, dan mempraktekkan perintah Allah.(al-Syaukani, 2014a, p. 462) Sedangkan menurut Abu Hayyan Al Andalusi dalam tafsirnya, kata "yaa Abati" merupakan salah satu tata bahasa yang tinggi dari segi kelembutan adab, dan cara memanggil orang yang lebih tua secara nasab dalam bahasa Arab.(al-Andalusiy, 1993, p. 182) Pada ayat setelahnya Asy Syaukani menyebutkan bahwa Nabi Ibrahim mengulang kembali seruannya pada ayahnya, dengan perkataan, "Wahai bapakku, Sesungguhnya telah datang kepadaku sebahagian ilmu pengetahuan yang tidak datang kepadamu", dalam ayat ini Nabi Ibrahim mengabarkan bahwa sebuah pengetahuan yang belum diketahui oleh ayahnya, dan dirinya telah memperbarui metode dalam memberikan nasehat, dan berusaha memperbaiki cara dalam memberikan petunjuk bagi orang-orang yang terlanjur tersesat.

Kemudian Nabi Ibrahim meminta ayahnya untuk mengikutinya, dan berkata "maka ikutilah aku, aku akan menunjukkan padamu jalan yang lurus" yaitu jalan lurus yang akan menyampaikan kepada tujuan dan menyelamatkan dari bahaya.(alSyaukani, 2014b, p. 462) Menurut Al Imam Al Alusiy, dalam ayat ini 
Nabi Ibrahim mulai mengajak ayahnya meninggalkan penyembahan berhala dan mengikuti kebenaran. Yang perlu diperhatikan adalah bahwa pada ayat ini Nabi Ibrahim tetap berdialog dengan ayahnya dengan kelembutan "Wahai ayahku sesungguhnya telah datang padaku sebagian ilmu pengetahuan yang tidak datang padamu". Nabi Ibrahim tidak mengatakan bahwa ayahnya adalah seorang yang bodoh, bahkan walaupun ayahnya benar-benar berada di puncak kebodohan, sebagaimana dirinya tidak merasa dan menamakan dirinya dalam dialog tersebut adalah seorang yang berilmu tinggi, terlebih merasa suci. Padahal dirinya adalah seorang nabi. Akan tetapi Nabi Ibrahim menampakkan kelembutan hatinya di hadapan ayahnya, agar ayahnya mau menerima ajakannya untuk meninggalkan penyembahan berhala. Maka kemudian dirinya berkata pada ayahnya "maka ikutilah aku, aku akan menunjukkan padamu jalan yang lurus" yaitu jalan yang lurus yang akan mengantarkan pada tujuan yang mulia dan menyelamatkan orang-orang yang menitinya dari kesesatan. Perkataan Ibrahim "telah datang padaku" menandakan bahwa pada saat itu Ibrahim telah diangkat menjadi seorang nabi. Para ulama berbeda pendapat mengenai yang dimaksud sebagai "ilmu" pada ayat di atas, ada yang menyebutkan bahwa ilmu yang dimaksud adalah ilmu tentang apa-apa yang dilarang Allah dan diwajibkan, ulama lain berpendapat bahwa ilmu yang dimaksud adalah ilmu tentang keadaan akhirat, termasuk perihal pahala dan dosa.(al-Alusiy, t.t., p. 97)

Ibnu 'Asyur menafsirkan ayat ini dalam kitab tafsirnya, bahwa Nabi Ibrahim mengulang pangglian "Ya Abati" untuk menghadirkan kesadaran ayahnya dalam menerima nasehat dan memperjelas point nasehat yang telah diberikan sebelumnya. Tata bahasa Nabi Ibrahim yang lembut sebagaimana yang ditafsirkan oleh Al Alusi di atas disebabkan karena ayah Nabi Ibrahim merupakan seorang tokoh besar di kalangan kaumnya, maka dirinya juga merasa bahwa dirinya 


\section{el-Tarbawj Muhammad Utama al-Faruqi}

seorang yang memiliki wawasan keilmuan yang tinggi, akan tetapi Nabi Ibrahim mengajaknya kepada ilmu yang bersumber pada wahyu dan kenabian. Tekhnik dialog seperti ini adalah dengan mengajak diskusi berdasarkan adanya kesamaan latar belakang diantara pendakwah dengan obyek dakwahnya.

Ibnu Asyur juga memberikan tafsir pada penggalan ayat أهديك) "ahdika shiratan sawiyya" "aku tunjukkan padamu jalan yang lurus", bahwa pada kata "jalan yang lurus" di dalam ayat ini terdapat dua jenis metafora dalam bahasa Arab yaitu maknawiyyah, yang menunjukkan salah satu sifat Nabi Ibrahim yaitu sebagai penunjuk jalan yang mengerti jalan dengan jelas dan metafora tashrihiyyah, yang juga nampak dalam kalimat "jalan yang lurus" yang bermakna sebagai kepercayaan yang benar, yang lurus dan akan mengantarkan pada kebenaran yang hakiki(Ibnu 'Asyur, 1985, p. 115)

Maka,kesimpulan tafsir pada ayat ini adalah bahwa Nabi Ibrahim memintanya untuk mengikutinya dengan perkataan "Maka ikutilah Aku, niscaya aku akan menunjukkan kepadamu jalan yang lurus.". yaitu jalan yang lurus, yang membuat sampai pada tujuannya dan membuat selamat dari bahaya. Kemudian Nabi Ibrahim menekankan kembali nasehatnya dengan tata bahasa yang lebih menekan dengan perkataan "Wahai bapakku, janganlah kamu menyembah syaitan" yaitu dengan mentaatinya, sesungguhnya menyembah berhala itu termasuk dari mentaati syaitan, lalu ditambahkan alasan atau sebab pelarangan itu dengan kalimat "Sesungguhnya syaitan itu durhaka kepada Tuhan yang Maha Pemurah." Yaitu ketika menolak sujud kepada Nabi Adam, maka barangsiapa yang mentaati siapapun yang telah mendurhakai Allah, maka dia telah durhaka pada Allah juga. Sedangkan orang yang bermaksiat dan mendurhakai Allah nikmat-Nya yang ada pada dirinya akan dicabut, dan akan berganti dengan hukuman. Kemudian pada ayat setelahnya, disebutkan bahwa Nabi Ibrahim berkata "Wahai 
bapakku, Sesungguhnya aku khawatir bahwa kamu akan ditimpa azab dari Tuhan yang Maha pemurah". Al Farra' mengartikan kata (إني أخاف)"inni akhofu" atau "aku takut" pada ayat ini dengan "aku tahu" sedangkan mayoritas ahli tafsir mengartikannya sesuai dengan arti asalnya, karena Nabi Ibrahim khawatir akan kematian ayahnya dalam keadaan kafir. Jikalau Nabi Ibrahim tidak khawatir, maka tentu saja Nabi Ibrahim tidak akan menasehati ayahnya. Maka, bisa dimaknai ketakutan atas sesuatu yang akan menimpa orang lain adalah prasangka atau perasaan dan firasat akan adanya sebuah bahaya yang akan menimpa orang lain tersebut. "maka dirimu akan menjadi kawan bagi setan", ditafsirkan bahwa jika ayah Nabi Ibrahim ini jika mentaati setan, maka dia akan bersamanya di neraka dengan keadaan terlaknat.

Maka, dengan sebab ikatan kebersamaan inilah, pengikut setan dengan setan disebut sebagai loyalitas, atau penyebutan loyalitas tersebut disebabkan keterikatan dalam keadaan keduanya yang secara bersama-sama mendapatkan adzab, dan tidak ada loyalitas yang hakiki sebagaimana firman Allah " para sahabat karib, pada hari itu adalah saling bermusuhan kecuali orang-orang yang bertaqwa".(Tim Kemenag RI, 2006) Ada juga yang menafsirkan bahwa (الو لاء) atau Al Wala' dalam ayat ini bermakna keterikutan, ada juga yang menafsirkannya dengan kedekatan, artinya ayah Azar menjadi dekat dengan setan ketika berada di neraka.(al-Syaukani, 2014b, p. 463) Menurut Ibnul Qoyyim, kata ( يمسّك ) "yamassaka" disini disebutkan dengan lafadz (مسنّ) "mass" atau menyentuh, dimana sentuhan merupakan interaksi jasad manusia yang paling lembut, dilanjutkan dengan kata (عذاب) "adzabun" yang dalam bahasa Arab berbentuk nakirah, artinya masih belum diketahui secara detail adzab yang dimaksud Nabi Ibrahim, ini adalah tata bahasa yang lembut yang digunakan oleh Nabi Ibrahim, kemudian dilanjutkan dengan menyebut "dari Yang Maha Pengasih", Nabi Ibrahim tidak menyebut 


\section{el-Tarbawj Muhammad Utama al-Faruqi}

"Yang Maha Perkasa" atau "Yang Maha Berkuasa”. Ini semua adalah tata bahasa paling lembut, begitu juga tata bahasa yang dipakai oleh seluruh Nabi dan Rasul dalam berdakwah pada kaumnya.(Muhammad \& al-Syami, 2008, p. 176)

Akan tetapi semua upaya berupa ajakan yang penuh dengan kasih sayang dan kelembutan seorang anak pada ayahnya, yang sangat khawatir dengan keselamatan ayahnya di dunia dan di akhirat ini justru mendapatkan respon yang kontradiktif dengan ajakan Nabi Ibrahim, “Berkata bapaknya: "Bencikah kamu kepada tuhan-tuhanku, Hai Ibrahim? jika kamu tidak berhenti, Maka niscaya kamu akan kurajam, dan tinggalkanlah aku buat waktu yang lama".(Tim Kemenag RI, 2006) Perkataan ayah Nabi Ibrahim “ Bencikah kamu pada tuhan-tuhanku, Hai Ibrahim ?" adalah kalimat tanya yang ditujukan untuk mencela dan memaki, bukan ditujukan untuk mencari sebuah jawaban sebagaimana pertanyaan yang selazimnya. Kemudian, ayah Nabi Ibrahim mengancamnya, "jika kamu tidak berhenti, maka niscaya kamu akan kurajam" ada perbedaan diantara ahli tafsir mengenai lafadz rajam yang dimaksud dalam ayat ini. apakah yang dimaksud adalah dirajam (dilempar) dengan batu, atau dihujat dengan lebih keras, ada juga yang menafsirkannya dengan pemukulan dan mengumumkan hal ini pada kaumnya yang saat itu adalah para penyembah berhala. Kemudian, ayah Nabi Ibrahim dalam ayat ini mengatakan "dan tinggalkanlah aku buat waktu yang lama". Para ulama tafsir menafsirkan bagian ayat ini bahwa makna waktu yang lama ini adalah waktu menurut Nabi Ibrahim, maka dimaknai pula bahwa ayah Nabi Ibrahim memintanya agar menjauhinya dengan kekhawatiran agar tidak terjadi hal-hal yang tidak diinginkan.(al-Syaukani, 2014b, p. 463)

Jika diperhatikan dalam ayat ini, sebenarnya Nabi Ibrahim sudah berhasil menggunakan komunikasi persuasif dalam menasehati ayahnya, dengan penuh kelembutan dan kasih sayang dan 
kekhawatiran akan keselamatan ayahnya di dunia dan akhirat, karena sebenarnya ayah Nabi Ibrahim,telah memberikan respon dengan menolak semua ajakan lembut Nabi Ibrahim dengan penolakan yang keras, disebabkan karena ayah Nabi Ibrahim tidak mampu membantah semua argumen logis yang telah disampaikan oleh Nabi Ibrahim. Jikapun Nabi Ibrahim belum berhasil dalam upaya menyadarkan ayahnya, pastilah ayahnya akan merespon dengan menyanggah semua argumen yang diberikan oleh Nabi Ibrahim, dan menjadi suatu hal yang tidak mungkin bahwa seorang nabi yang dipilih oleh Allah gagal dalam menjalankan tugas. Terlebih kisah ini didokumentasikan secara sistematis dalam Al Quran.

Kemudian setelah melihat kerasnya sikap dan respon ayahnya padanya, maka Nabi Ibrahim berkata, "Semoga keselamatan dilimpahkan kepadamu, aku akan memintakan ampun bagimu kepada Tuhanku. Sesungguhnya Dia sangat baik kepadaku".(Tim Kemenag RI, 2006) Kata (ســـلام عـلــ (salamun alayk" memang jika diterjemahkan dalam bahasa Indonesia seperti penafsiran salam biasa, akan tetapi para ulama tafsir bersepakat bahwa ini bukanlah salam antar muslim, melainkan sebagai sebuah pernyataan saling berpisah dengan cara yang baik. Setelah menghadapi penolakan yang sangat keras seperti ini, Nabi Ibrahim kemudian memberikan penghormatan perpisahan sebelum meninggalkan ayahnya, sebagaimana perintah ayahnya di ayat sebelumnya, sekaligus usaha terakhir sebelum Nabi Ibrahim meninggalkan ayahnya untuk memberinya nasehat dan agar ayahnya memperlembut sikapnya, dengan memohonkan ampun untuknya, karena Nabi Ibrahim yakin bahwa Allah sangat baik dan lembut padanya.(al-Syaukani, 2014b, p. 463) Sedangkan Ibnul Jauzi menafsirkan ayat ini bahwa makna ( سلام) "salamun" di ayat ini bahwa Nabi Ibrahim menyampaikan itu untuk perpisahan dengan damai tanpa adanya permusuhan antara dirinya dan ayahnya. Maka, dirinya setelah itu mengatakan (سـأسـتغفركم) "saastaghfirukum", di kalimat ini 


\section{el-Tarbawj Muhammad Utama al-Faruqi}

ada dua pendapat ulama tafsir, yang pertama menyatakan bahwa Nabi Ibrahim memohonkan ampun pada Allah, sebagaimana yang dipahami dalam terjemah, dan yang kedua adalah memberikan peringatan dengan penyebutan permohonan ampun (istighfar) kepada Allah, sedangkan istighfar merupakan suatu hal yang tidak dipikirkan sedikitpun oleh seorang penyembah berhala. Pada akhir ayat, (إنّه) "Innahu” ada setidaknya tiga perkataan ulama tafsir pada makna (حفيا) "khafiya", yaitu lembut, maha penyayang dan maha baik, yang selalu mengabulkan doa.(Ibnu al-Jauzi, 2002, p. 887)

Kemudian, setelah berpamitan dan menyampaikan nasehat serta doa pada ayahnya, Nabi Ibrahim melanjutkan pernyataannya , " Dan aku akan menjauhkan diri darimu dan dari apa yang kamu seru selain Allah, dan aku akan berdoa kepada Tuhanku, Mudah-mudahan aku tidak akan kecewa dengan berdoa kepada Tuhanku".(Tim Kemenag RI, 2006) Nabi Ibrahim menyatakan bahwa dirinya akan berhijrah demi agamanya, menjauhi kaumnya beserta dengan praktik penyembahan berhala yang mereka adakan, karena nasehatnya tidak

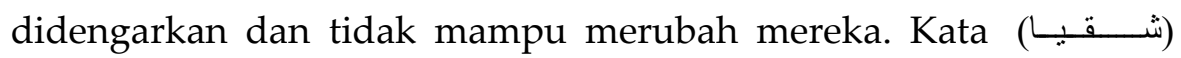
"syaqiyya" bisa bermakna kecewa (خـائسب) (kha'ib) atau enggan (عساص)('ashi). Baik enggan dalam arti bahwa dirinya enggan berdoa pada Allah, atau dalam arti yang lain Allah pasti enggan dalam mengabulkan doanya. Para ulama tafsir mengatakan bahwa maksud Nabi Ibrahim dalam doa ini adalah, bahwa dirinya berdoa pada Allah agar memberinya anak-anak dan keluarga baru yang membuat dirinya lebih tenang, ada juga yang dimaksud adalah doa agar ayahnya segera diberi hidayah oleh Allah dan bertaubat. Akan tetapi, pendapat pertama lebih tepat, melihat konteks pada ayat ini dan pada ayat setelahnya.(al-Syaukani, 2014b, p. 464) Allah berfirman, "Maka ketika Ibrahim sudah menjauhkan diri dari mereka dan dari apa yang mereka sembah selain Allah, Kami anugerahkan kepadanya Ishak, dan Ya'qub. dan masing-masingnya Kami angkat menjadi Nabi".(Tim 
Kemenag RI, 2006) Asy Syaukani memberikan tafsir pada ayat "Maka ketika Ibrahim sudah menjauhkan diri dari mereka dan apa yang mereka sembah selain Allah, Kami anugerahkan kepadanya Ishak dan Ya'qub" yaitu dengan memberikan mereka sebagai anugrah berupa keluarga dan anak sebagai ganti dari apa yang ditinggalkan oleh Ibrahim".(al-Syaukani, 2014b, p. 464)

Kemudian akhir dari kisah dialog Nabi Ibrahim dengan ayahnya pada Surat Maryam Allah berfirman, "Dan Kami anugerahkan kepada mereka sebagian dari rahmat Kami dan Kami jadikan mereka buah tutur yang baik lagi tinggi". (Tim Kemenag RI, 2006) Asy Syaukani menafsirkan ayat ini bahwa penyebutan anugrah atau rahmat setelah Allah berfirman bahwa mereka dipilih oleh Allah untuk menjadi nabi, adalah karena kenabian merupakan sebuah karunia dari Allah. Walaupun ada juga yang menafsirkan bahwa makna rahmah atau karunia pada ayat ini adalah harta, anak-anak dan juga kitab / wahyu. Pada akhir ayat ini disebutkan bahwa Allah menjadikan mereka buah tutur yang baik lagi tinggi. Asy Syaukani menafsirkan ini sebagai pujian yang baik. Sedangkan penisbatan mereka pada (صـدق) (shidq) bermakna baik dan jujur serta tinggi merupakan salah satu bentuk pujian Allah pada perkataan manusia.(al-Syaukani, 2014b, p. 464) As Samarqandiy juga memberikan tafsir yang lebih detail mengenai dua ayat ini, As Samarqandiy mengatakan bahwa setelah Nabi Ibrahim memutuskan untuk pergi menjauh dan menyatakan pernyataan di atas, Nabi Ibrahim berjalan menuju Baitul Maqdis dan menetap disana bersama istrinya. Yang kemudian Allah memuliakannya dengan memberinya dua orang putra, yaitu Ishaq. Lalu dari Ishaq, lahir pula keturunan yang lain yaitu Ya'qub. Sebagian ahli hikmah kemudian mengatakan bahwa barangsiapa yang berhijrah (berubah atau berpindah tempat) untuk mencari ridha Allah, Allah akan memuliakannya di dunia dan akhirat. Sebagaimana Nabi Ibrahim yang berpindah, menjauh dari kaumnya yang telah terlanjur tersesat 


\section{el-Tarbawj Muhammad Utama al-Faruqi}

dalam rangka mencari keridhaan Allah, maka Allah memuliakannya dengan mengganti kaum yang ditinggalkannya (termasuk keluarganya) itu dengan dua orang nabi dari keturunannya, yaitu Ishaq dan Ya'qub.

Kemudian pada firman Allah "dan semuanya Kami jadikan sebagai nabi" yaitu Ibrahim, Ishaq dan Ya'qub, telah Allah berikan anugrah dengan kenabian, lalu dilanjutkan oleh As Samarqandi pada ayat setelahnya tafsir dari kata "dan telah Kami berikan pada mereka sebagian rahmat Kami", yaitu : dari sebagian rahmat Allah adalah harta dan anak-anak di dunia dan juga firman Allah "dan telah Kami jadikan pada mereka lisan yang jujur dan juga mulia" bermakna bahwa telah Allah muliakan dengan pujian yang indah dan baik.(alSamarqandiy, 1993, p. 325)

\section{Seni Dialog Nabi Ibrahim: Teladan Akhlaq Para Pendakwah}

Tampak dengan jelas pada surat Maryam ayat 41-50 di atas, bahwa Nabi Ibrahim memakai metode dakwah berupa dialog, dengan mengedepankan rasa kasih sayang dan kelembutan, karena hanya dengan cara itulah sebuah nasehat dan dakwah disampaikan kepada masyarakat, terlebih lagi pada keluarga dekat. Hal tersebut membutuhkan kesabaran yang tinggi, karena sewajarnya seseorang yang melihat hal yang tidak disukainya akan cenderung lebih suka terburu-buru untuk menyalahkan, atau memberi label pada pelaku. Hal ini sering menjadi poin penting dalam penyampaian sebuah nasehat sebagai bentuk respon atas fenomena dalam masyarakat yang terjadi. Terlebih lagi jika itu baru sebatas kabar yang tidak diketahui asalnya, atau tidak bisa dibenarkan.

Kemudian, Nabi Ibrahim juga berusaha memilih pilihan kata yang sesuai dan beradab. Dengan penuh penghormatan, dan tidak merendahkan obyek dakwahnya. Tidak pula disampaikan dengan merendahkan obyek dakwah, sekalipun secara kenyataan obyek 
dakwah tersebut memang melakukan kesalahan terbesar, akan tetapi hal itu harus tetap dihadapi dengan kelembutan dan ketenangan. Nabi Ibrahim juga tidak tergesa-gesa dalam membujuk ayahnya agar meninggalkan perbuatannya. Akan tetapi dengan cara bertahap, perlahan dengan rapi dan terukur. Jika diperhatikan, ada empat kali Nabi Ibrahim memanggil dan merayu ayahnya dengan kelembutan "Yaa Abati". Pada pertama kalinya, Nabi Ibrahim bertanya agar ayahnya turut menggunakan logika dalam melihat kepercayaannya tersebut, setelah ayahnya ikut berpikir mengenai kepercayaannya itu, Nabi Ibrahim merayunya dengan sebuah informasi tentang sesuatu yang menarik, agar ayahnya turut membahas itu dan meninggalkan kepercayaannya, lalu barulah Nabi Ibrahim melarang ayahnya untuk menyembah setan, yang direpresentasikan dalam wujud berhala pada saat itu. Dan pada akhirnya, Nabi Ibrahim mengajak ayahnya dengan sisi afeksinya. Disinilah perlunya seorang pendakwah mengetahui kondisi umat yang menjadi obyek dakwahnya, untuk kemudian menyusun strategi dan metode dalam menyampaikan dakwahnya.

Dari kisah dialog Nabi Ibrahim di atas adalah, bahwa apapun yang terjadi dalam melakukan dakwah, akhlaq mulia seorang pendakwah tidak boleh hilang. Bahkan walaupun menghadapi keadaan yang sangat sulit dan mendapat perlakuan yang keras sekalipun. Akan tetapi, menanamkan akhlaq yang baik tidak bisa dilakukan dengan cepat dan terburu-buru. Melainkan membutuhkan waktu yang panjang dan metode yang tepat.

Jika diperhatikan menurut ilmu sosiologi, ada istilah revolusi dan evolusi. Revolusi adalah sebuah istilah yang menggambarkan perubahan dalam masyarakat yang cepat dan cenderung terburuburu, sehingga berpotensi menimbulkan banyak korban dan kerusakan. Sedangkan evolusi sebaliknya, perubahan dalam masyarakat yang perlahan akan tetapi pasti. Dan dakwah adalah salah satu bentuk upaya evolusi dalam masyarakat Islam, berdasar 


\section{el-Tarbawj Muhammad Utama al-Faruqi}

karakterisitik dakwah secara fundamental dan juga pertimbangan demi keterlanjutan dakwah dalam masyarakat tersebut. Sedangkan istilah revolusi tidak bisa disandingkan dengan akhlaq baik secara makna etimologis atau terminologis. Karena penanaman akhlaq yang baik dalam masyarakat, terlebih yang bersifat majemuk tidak bisa dilakukan dengan cepat. Akan tetapi, sebaliknya akhlaq yang buruk mudah sekali disebarkan dalam masyarakat dalam waktu yang singkat, bisa diperhatikan dalam realita sehari-hari dalam sebuah masyarakat, terlebih lagi di kalangan generasi muda yang pada umumnya sudah jauh dari kegiatan kajian agama, dan lebih dekat dengan hal-hal yang merusak moral.

Yang terpenting dari kisah dialog Nabi Ibrahim dengan ayahnya di atas adalah, bahwa dakwah dimulai dari lingkungan keluarga terlebih dahulu, sebelum ke masyarakat. Akan tetapi, tidak kemudian dakwah masyarakat tidak akan dilakukan sampai keluarga berubah, melainkan skala prioritas dalam menentukan obyek dakwah.

\section{Kesimpulan}

Tidaklah Allah subhanahu wa ta'ala mengutus para nabi dan rasul kecuali agar menjadi teladan bagi generasi setelahnya, apalagi jika kisah mereka secara detail telah disebutkan dalam Al Quran, dan menyangkut salah satu hal terpenting dalam agama Islam, yaitu dakwah. Nabi Ibrahim -'alayhis salam- merupakan salah satu sosok nabi dan rasul teladan dan menginspirasi dengan metode dakwahnya yang menggunakan kecerdasan intelektual dan emosionalnya. Cara dakwahnya yang sabar dan elegan, baik lewat dialog dengan ayahnya seperti yang telah dijelaskan dalam surat Maryam ayat 41 hingga 50, atau dialog-dialog lain dengan kaumnya, dengan membuat para kaumnya menggunakan logika mereka sendiri untuk mengajak para kebenaran. Tanpa mencela dan membuat mereka lari dari agama. 
Keteladanan Nabi Ibrahim ini selayaknya menjadi sebuah bekal dan pelajaran penting bagi para pendakwah, terlebih khusus di era sekarang dan di tanah air, dimana karakteristik umat Islam di Indonesia adalah karakteristik yang lembut, ramah, dan gotong royong.

\section{Daftar Pustaka}

Al-Alusiy, M. S. (t.t.). Ruhul Ma'ani (Vol. 16). al-Muniriyah.

Al-'Ammar, H. bin N. bin A. R. (2018). Asalibud Da'wah alIslamiyyah al-Mu'ashirah. Dar Kunuz Isybilia.

Al-Andalusiy, A. H. (1993). Tafsir al-Bahr al-Muhith (Vol. 6). Beirut.

Al-Bukhari, M. bin I. (2011). Shahih al-Bukhari. Dar al-Hadits.

Al-Razi, M. bin U. F. (1981). Tafsir al-Fakhrur Razi (Vol. 21). Dar al-Fikr.

Al-Samarqandiy, A. L. N. bin M. (1993). Bahrul Ulum (Vol. 3). Dar al-Kutub al-Ilmiyyah.

Al-Syaukani, M. bin A. bin M. (2014a). Fathul Qodir (Vol. 1). Dar al-Wafa.

Al-Syaukani, M. bin A. bin M. (2014b). Fathul Qodir (Vol. 3). Dar al-Wafa.

Al-Utsaimin, M. bin I. (2013). Ushul fi al-Tafsir. Dar Ibn Hazm.

Ali, A. A. M. bin N. (2004). Laka Ayyuda al-Da'i. Maktabatul Ulum wal Hikam.

Ibnu al-Jauzi, A. al-F. J. (2002). Zaadul Masir fi Ilmi al-Tafsir. Dar Ibn Hazm.

Ibnu 'Asyur, M. al-Thahir. (1985). Tafsir al-Tahrir wa al-Tanwir (Vol. 16). al-Dar al-Tunisiyah.

Muhammad, Y. al-Sayyid, \& al-Syami, S. A. (2008). Badi'atu alTafsir: Al-Jami' Lima Fassaru al-Imam Ibnu al-Qoyyim al-Jauziyah (Vol. 2). Dar Ibnu Jauzi.

Syakir, A. (2005). Umdatu al-Tafsir 'an al-Hafidz Ibnu Katsir: Mukhtashar Tafsir al-Qur'an al-'Adzim (Vol. 2). Dar al-Wafa. 


\section{el-Tarbawj Muhammad Utama al-Faruqi}

Tim Kemenag RI. (2006). Al-Qur'an dan Terjemahannya. Diponegoro.

Zaydan, A. K. (2005). Ushul al-Da'wah (10th ed.). Muassasah alRisalah. 